\title{
A full genome scan for gastric cancer
}

\author{
M Aoki, Y Yamamura, H Noshiro, K Sakai, J Yokota, T Kohno, T Tokino, S Ishida, S Ohyama, \\ I Ninomiya, K Uesaka, M Kitajima, S Shimada, S Matsuno, M Yano, M Hiratsuka, H Sugimura, \\ F Itoh, T Minamoto, Y Maehara, S Takenoshita, T Aikou, H Katai, K Yoshimura, T Takahashi, \\ K Akagi, M Sairenji, K Yamamoto, T Sasazuki
} $\mathrm{t}$ is generally accepted that multiple factors play a role in gastric carcinogenesis, including diet, ${ }^{12}{ }^{2}$ lifestyle, ${ }^{3}$ infectious agents such as Helicobacter pylori $\left(H\right.$. pylori),${ }^{45}$ and genetic factors as well as gene-environment interactions. ${ }^{67}$ Although the continuous decrease in the incidence of gastric cancer in recent decades can be explained by changing lifestyle, diet habits, and reduced $H$. pylori infection, the fact that some individuals develop gastric cancer while others do not under similar environmental exposures suggests that genetic predisposition plays an important role in the pathogenesis of this disease. In addition, familial clustering of cases of gastric cancer, a higher incidence of the disease among the relatives of patients than among matched controls, and a more common coincidence of the disease in homozygotic than in heterozygotic twins, also supports genetic links with gastric cancer. ${ }^{8-10}$

In contrast with the vast amount of accumulated information on environmental factors, little is known about the genetic factors linked to gastric cancer. Several studies have reported disease susceptible loci for gastric cancer, based on association analysis of candidate genes involved in DNA repair, detoxification, or the immune system. ${ }^{11}$ Studies on familial clustering of gastric cancer revealed germline mutations in CDHI, ATM, and MET. ${ }^{12-14}$ In addition, gastric cancer frequently occurs in family members with monogenic diseases such as hereditary non-polyposis colorectal cancer, Li-Fraumeni syndrome, familial adenomatous polyposis, and Peutz-Jeghers syndrome. ${ }^{15-18}$ However, these polymorphisms and/or mutations cannot explain the overall genetic components of gastric cancer.

It is now feasible to screen the entire human genome for genes exerting a major effect on susceptibility to multifactorial diseases. Because gastric cancer, like many complex diseases, exhibits genetic heterogeneity, we carried out a genome-wide linkage study to search for possible susceptibility loci related to gastric cancer, using a non-parametric sibpair method in 170 affected sibpairs from 142 Japanese families. The data we obtained yielded chromosomal regions that are likely to harbour human gastric cancer susceptibility genes.

\section{METHODS}

Families

A total of 297 gastric cancer patients, including 170 informative sibpairs, from 142 Japanese families were recruited with the approval of the Ethical Committee of Kyushu University, Fukuoka, Japan. Nine of the families included three affected sibs and two included four affected sibs. The mean age at diagnosis of these 297 patients was 57.0 years and the male to female ratio was 1.69. All participants provided written informed consent. The diagnosis of gastric cancer was confirmed by pathological records

\section{Key points}

- We carried out a genome-wide screen to search for regions of the human genome containing gastric cancer susceptibility genes in 170 affected sibpairs from 142 Japanese families, using 392 microsatellite markers spanning the entire genome.

- Non-parametric linkage analysis of the entire data set, using the MAPMAKER/SIBS program, identified four regions, 1p32, 2q33-q35, $11 p 13-p 14$, and 21q21, showing evidence for linkage with a multipoint logarithm of odds (LOD) score of $\geqslant 1.18(p \leqslant 0.01)$. The strongest signal was observed on chromosome 2q33-35 (multipoint and two point LOD scores of 1.74 and 1.98, respectively).

- In an analysis of a subgroup with proximal gastric cancer, the signal of linkage to 2q33-q35 increased to multipoint and two point LOD scores of 3.61 and 2.93, respectively. Simulation studies revealed that this finding exceeded that expected by chance $(p=0.002)$. Furthermore, a linkage signal to chromosome 2q33-35 was confirmed by additional markers and the MERLIN program (multipoint LOD scores of 3.38 and 2.66 , respectively). Our results suggest the presence of a gastric cancer susceptibility locus on this chromosome.

and/or by examination of medical records at hospitals where the patients were surgically treated.

\section{Genotyping}

Genotyping was carried out as described. ${ }^{19}$ Briefly, genomic DNA was extracted from total peripheral blood using QIAamp DNA Blood Mid Kits (Qiagen, Valencia, CA, USA). ABI PRISM Linkage Mapping Set Version 2 (Applied Biosystems, Foster City, CA, USA) was used for amplification of 392 microsatellite markers spanning the entire human genome with an average interval of $10 \mathrm{cM}$. PCR reaction was carried out in a $15 \mu \mathrm{l}$ volume using reagent concentrations and temperature profiles as recommended by the manufacture (Applied Biosystems). Amplification of the expected size of double strand DNA was confirmed by agarose gel electrophoresis. The fluorescence labelled PCR products were pooled (10-20 markers/pool) and electrophoresis was carried out using the ABI PRISM model 377 or 3100 DNA sequencer equipped with Genescan software (Applied Biosystems) for

Abbreviations: LOD, logarithm of odds 

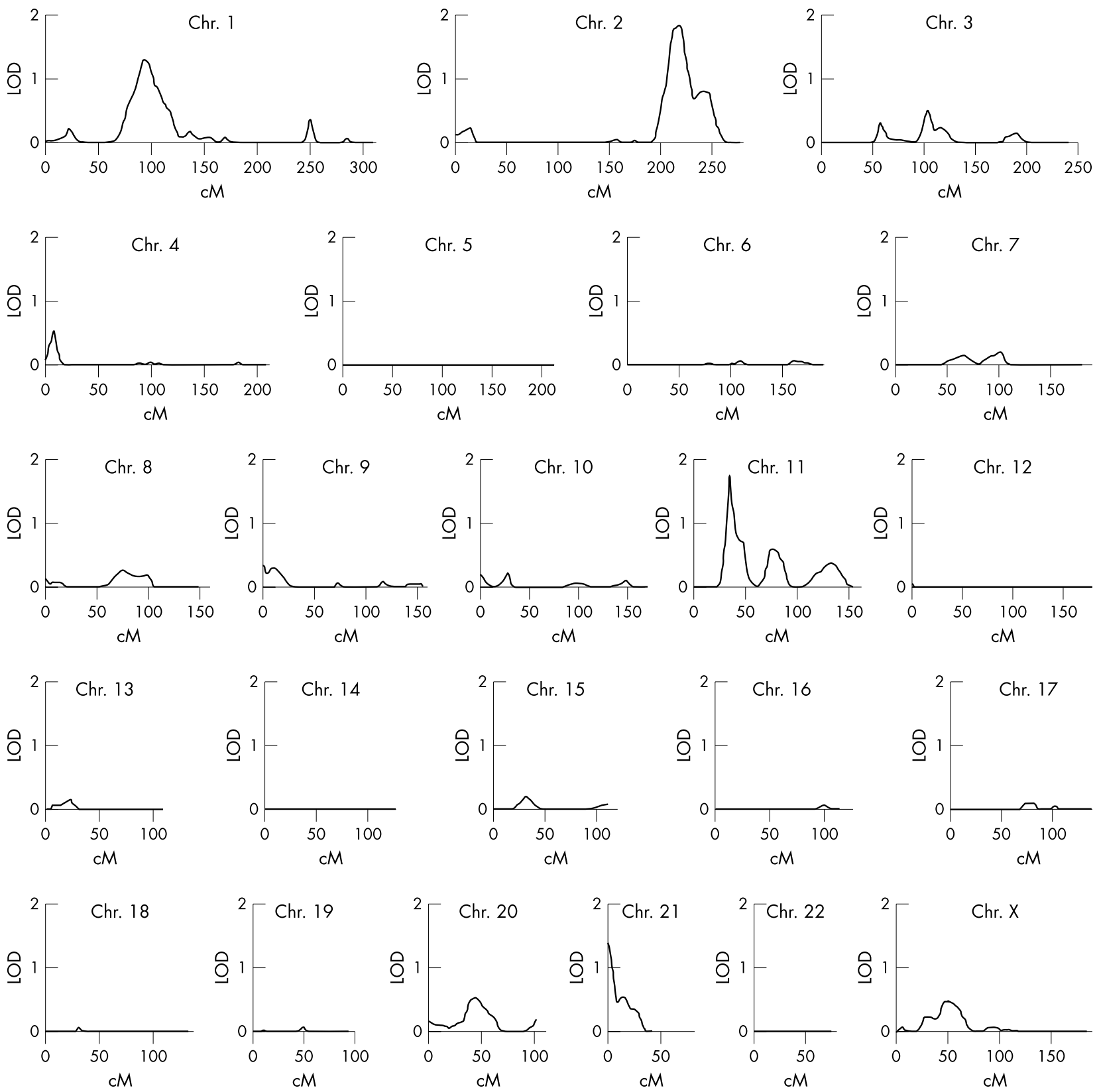

Figure 1 Genome-wide scan for gastric cancer. Multipoint linkage analysis was carried out using 392 microsatellite markers for the entire set of samples (170 sibpairs) using the MAPMAKER/SIBS program. The horizontal axis shows the distance from the p terminus (cM). Chr., chromosome.

genotyping. The marker alleles were visualised using Genotyper software (Applied Biosystems).

\section{Statistical analysis}

Multipoint or two point analysis for logarithm of odds (LOD) scores was carried out on all possible weighted 170 pairs, using the MAPMAKER/SIBS or MERLIN program. Multipoint LOD scores $\geqslant 1.18(\mathrm{p} \leqslant 0.01)$ were identified as nominal evidence for linkage, LOD scores $\geqslant 2.2$ as suggestive $(p \leqslant 0.0007)$, and LOD scores $\geqslant 3.6$ as significant $(\mathrm{p} \leqslant 0.00002){ }^{20}$

For a chromosomal locus showing the highest multipoint LOD score, simulation studies were carried out to evaluate a genome-wide significance of linkage using the MERLIN program which generates simulated chromosomes conditional on family structure, actual marker spacings, and allele frequencies, as well as missing data patterns. ${ }^{21}$

\section{Subgroups stratification}

Since numerous reports indicate different etiologies in subsites or histological subtypes, ${ }^{3} 72223$ linkage analyses were carried out for subgroups stratified on tumour localisation and histology. As it can be assumed that a sibpair shares the same genetic factors involved in gastric cancer, subgroups included sibpairs where at least one sib met the criteria. Tumour localisation was classified according to the rules of the Japanese Gastric Cancer Association ${ }^{24}$ with cancer developing in the upper third of the stomach designated as proximal gastric cancer and the rest as distal. Age at diagnosis (younger than 50 years) was also considered for subgroup stratification. Of the 170 affected sibpairs with gastric cancer, 25 and 108 were classified into the proximal and distal subgroups, respectively, 11 were included in both subgroups, one did not met the criteria, and clear information of tumour localisation was not obtained for 47 sibpairs. 
Regarding histological type, 76 and 62 sibpairs were classified into diffuse and intestinal subgroups, respectively, 32 were included in both subgroups, and clear histological information was not obtained for 64 sibpairs. A total of 53 sibpairs met the criteria that at diagnosis at least one sib was less than 50 years old.

\section{RESULTS AND DISCUSSION}

The entire set of 170 informative affected sibpairs with gastric cancer was initially analysed. Figure 1 shows the multipoint LOD scores for gastric cancer as a qualitative trait with markers on all chromosomes, determined using the MAPMAKER/SIBS program. Four chromosomal regions, 1p32, 2q33-2q35, 11pl3-14, and 21q21, were identified as providing nominal evidence for linkage with multipoint LOD scores of $\geqslant 1.18$, corresponding to $p \leqslant 0.01$. The highest multipoint LOD score was observed on chromosome $2 \mathrm{q} 33$ and 1lp14 (both D2S325 and D11S904 showed an LOD of $1.74, \mathrm{p}=0.002$ ). Two point analysis revealed an additional chromosomal region, lq32, with an LOD score of $\geqslant 1.18$ (D1S425, LOD = 2.16). D2S325, D11S904, and D21S1256 had LOD scores of $\geqslant 1.18$ in multipoint and two point analyses. The two point LOD score of D2S325 was higher than that of D11S904 (1.98 and 1.37, respectively). None of the regions, however, reached the threshold for suggestive $(\mathrm{LOD}=2.2$, $\mathrm{p}=0.0007)$ or significant $(\mathrm{LOD}=3.6, \mathrm{p}=0.00002)$ evidence for linkage. ${ }^{20}$

Gastric cancer has been classified into two subgroups based on tumour localisation (cardia or non-cardia) and into two histological subtypes (intestinal or diffuse). Most gastric cancer develops in the distal portion of the stomach (noncardia) and a spontaneous decrease in the incidence of this type has been observed in many populations, whereas the incidence of cancer originating in the gastric cardia appears to be relatively stable. ${ }^{22} 25$ The intestinal type seems to be highly prevalent in populations with high rates of gastric cancer. By contrast, the diffuse type is predominant in populations with a low incidence of the disease. ${ }^{27} 28$ These diverging trends in incidence imply different etiologies in both subsites and histological subtypes of gastric cancer. In order to examine if the weak linkage of gastric cancer with the chromosomal regions observed in the entire data set shows subsite or histological subtype specificity, linkage analyses were carried out for stratified subgroups. Six chromosomal regions exceeding a multipoint LOD score of 1.18 were found in an analysis of the proximal gastric cancer subgroup (chromosomes lp32-p33, 2q31-q36, 5q1l-q12, 8p23, 19p13, and Xpl1; table 1). In particular, the markers on chromosome 2q31-q36 showed LOD scores $>2.0$, while that of D2S325 (chromosome 2q33.3) was $3.61(\mathrm{p}<0.00002)$,

Table 1 Summary of regions with multipoint or two point LOD scores of $\geqslant 1.18$ in subgroup analysis

\begin{tabular}{|c|c|c|c|c|c|c|c|c|}
\hline & \multirow[b]{2}{*}{ Marker name } & \multirow{2}{*}{$\begin{array}{l}\text { Cytogenic } \\
\text { position }(\mathrm{CM})^{*}\end{array}$} & \multirow{2}{*}{$\begin{array}{l}\text { Marker } \\
\text { position* }\end{array}$} & \multirow{2}{*}{$\begin{array}{l}\text { Heterozygosity } \\
\text { (\%) }\end{array}$} & \multicolumn{2}{|c|}{ Multipoint data† } & \multicolumn{2}{|c|}{ Two point data } \\
\hline & & & & & LOD & Point wise $p$ & $\overline{L O D}$ & Point wise $p$ \\
\hline \multirow[t]{17}{*}{$\begin{array}{l}\text { Proximal, } \\
n=25 \ddagger\end{array}$} & $\begin{array}{l}\text { Chromosome } 1 \\
\text { D1S2797 } \\
\text { D1S2890 }\end{array}$ & $\begin{array}{l}77.6 \\
87.7\end{array}$ & $\begin{array}{l}1 \mathrm{p} 33 \\
1 \mathrm{p} 32.2\end{array}$ & $\begin{array}{l}73.8 \\
76.9\end{array}$ & $\begin{array}{l}1.66 \\
1.60\end{array}$ & $\begin{array}{l}0.0028 \\
0.0033\end{array}$ & $\begin{array}{l}(0.90) \\
(0.60)\end{array}$ & $\begin{array}{l}0.021 \\
0.048\end{array}$ \\
\hline & Chromosome 2 & & & & & & & \\
\hline & D2S364 & 186.2 & $2 q 31.3$ & 79.9 & 2.13 & 0.00086 & 1.21 & 0.0091 \\
\hline & D2S117 & 194.5 & $2 q 32.3$ & 89.2 & 2.02 & 0.0012 & $(1.10)$ & 0.012 \\
\hline & D2S325 & 210.9 & $2 q 33.3$ & 74.5 & 3.61 & 0.00002 & 2.93 & 0.0001 \\
\hline & D2S2382 & 220.7 & $2 q 35$ & 51.1 & 2.59 & 0.00028 & $(0.57)$ & 0.053 \\
\hline & $\mathrm{D} 2 \mathrm{~S} 126$ & 220.1 & $2 q 36.1$ & 76.7 & 2.11 & 0.00091 & 1.60 & 0.0033 \\
\hline & Chromosome 5 & & & & & & & \\
\hline & D5S407 & 64.7 & $5 q 11.2$ & 82.8 & 1.18 & 0.0098 & $(0.52)$ & 0.061 \\
\hline & D5S647 & 74.7 & $5 q 12.3$ & 82.7 & 1.57 & 0.0036 & 2.16 & 0.0008 \\
\hline & Chromosome 8 & & & & & & & \\
\hline & D8S277 & 8.3 & 8p23.1 & 83.2 & 1.78 & 0.0021 & 1.24 & 0.0083 \\
\hline & Chromosome 19 & & & & & & & \\
\hline & D19S884 & 26.0 & 19p13.2 & 80.0 & 1.31 & 0.0071 & 1.21 & 0.0090 \\
\hline & D19S220 & 61.4 & $19 q 13.13$ & 90.7 & $(0.86)$ & 0.023 & 2.22 & 0.0007 \\
\hline & Chromosome X & & & & & & & \\
\hline & DXS993 & 66.1 & Xp11.4 & 74.5 & 1.21 & 0.0092 & $(0.25)$ & 0.14 \\
\hline \multirow{6}{*}{$\begin{array}{l}\text { Distal, } \\
n=108\end{array}$} & Chromosome 2 & & & & & & & \\
\hline & D2S162 & 20.0 & $2 \mathrm{p} 25.1$ & 78.1 & $(0.34)$ & 0.11 & 1.46 & 0.0048 \\
\hline & D2S325 & 204.5 & $2 q 33.3$ & 74.5 & 1.41 & 0.0055 & 1.38 & 0.0059 \\
\hline & Chromosome 11 & & & & & & & \\
\hline & D115904 & 33.6 & $11 \mathrm{p} 14.2$ & 16.3 & 1.36 & 0.0061 & 1.65 & 0.0029 \\
\hline & D1 $1 S 935$ & 49.6 & $11 \mathrm{p} 13$ & 75.5 & $(0.44)$ & 0.077 & 1.67 & 0.0028 \\
\hline \multirow{4}{*}{$\begin{array}{l}\text { Diffuse, } \\
n=76\end{array}$} & Chromosome 11 & & & & & & & \\
\hline & D115904 & 33.6 & $11 \mathrm{p} 14.2$ & 16.3 & 2.12 & 0.0009 & 1.57 & 0.0035 \\
\hline & D11S935 & 45.9 & $11 \mathrm{p} 13$ & 75.5 & 1.45 & 0.0049 & 3.51 & 0.00003 \\
\hline & D11S1314 & 73.6 & $11 \mathrm{q} 13.4$ & 74.6 & $(0.81)$ & 0.027 & 1.37 & 0.0060 \\
\hline \multirow{3}{*}{$\begin{array}{l}\text { Intestinal, } \\
n=62\end{array}$} & Chromosome 21 & & & & & & & \\
\hline & $\mathrm{D} 21 \mathrm{~S} 1256$ & 8.6 & $21 \mathrm{q} 21.1$ & 63.5 & 1.35 & 0.0064 & $(1.16)$ & 0.01 \\
\hline & D21S1914 & 19.4 & $21 q 21.2$ & 87.7 & 1.23 & 0.0087 & (1.07) & 0.013 \\
\hline \multirow{4}{*}{$\begin{array}{l}\text { Age at } \\
\text { diagnosis } \\
<50 \\
n=53\end{array}$} & Chromosome 2 & & & & & & & \\
\hline & D2S325 & 204.5 & $2 q 33.3$ & 74.5 & 1.96 & 0.0013 & $(1.08)$ & 0.013 \\
\hline & D2S2382 & 220.7 & $2 q 35$ & 51.1 & 1.59 & 0.0034 & (0.51) & 0.063 \\
\hline & $\begin{array}{l}\text { Chromosome } 21 \\
\text { D21S1256 }\end{array}$ & 8.6 & $21 \mathrm{q} 21.1$ & 63.5 & 1.34 & 0.0066 & 1.31 & 0.0070 \\
\hline
\end{tabular}

*Marker positions are from the database of a GenethonMap in the National Center for Biotechnology Information (http://www.ncbi.nlm.nih.gov/). tEntries with an LOD score of $<1.18$ are in parentheses.

$\ddagger$ Number of sibpairs analysed. 
which was beyond the strict level for genome-wide statistical significance. ${ }^{20}$ This marker showed an LOD score of 2.93 $(p=0.0001)$ in a two point analysis. Simulation studies using the MERLIN program for the proximal subgroup revealed that only two replicates demonstrated multipoint LOD scores of >3.6 for D2S325 among 1000 replicates of simulation, suggesting a genetic link between the proximal subgroup and this marker. To further confirm this finding, an additional seven markers covering $50 \mathrm{cM}$ of chromosome 2q31-q36 were typed and reanalysis including the initial markers on this region was carried out (fig 2). This additional mapping revealed that the LOD scores for $2 \mathrm{q} 33$-q35 were greater than 2.2 , confirming evidence suggestive of linkage. ${ }^{20}$ The strongest linkage signal was obtained for D2S325 with an LOD score of 3.37. The MERLIN program, which calculates the LOD score using the Kong and Cox $\delta$ method under an exponential model, was applied to region 2q33-q35 for additional information. It was found that D2S325 showed a multipoint LOD score of 2.66 ( $p=0.0002$ ) (fig 2, dotted line). Thus, even though the sample size was small, 2q33-q35 was suggested to be a gastric cancer susceptibility locus, especially for tumours localised in the proximal region of the stomach. On the other hand, two chromosomal regions, 2q33 and 11pl4, showed weak linkage in an analysis of the distal gastric cancer subgroup (table 1).

When histological subgroups were analysed, 11p13-14 and $21 q 21$ showed linkage in the diffuse and intestinal subgroups, respectively (table 1). In particular, markers D11S904 and D11S935 on 11p13-p14 showed moderate linkage signals in multipoint and two point analyses in the diffuse type (multipoint $\mathrm{LOD}=2.12$ and 1.45 , two point $\mathrm{LOD}=1.57$ and 3.51 , respectively). The etiology of the diffuse type of gastric cancer is presumed to be less affected by environmental factors than the intestinal type. A study reporting association of the $\mathrm{CDHl}$ germline mutations with the development of the diffuse type provided the first evidence that gastric cancer had a molecular basis in predisposed families. ${ }^{12}$ Our data suggest that genetic polymorphism in other genes on chromosome 11pl3-pl4 may be responsible for tumourigenesis of the diffuse type of gastric cancer. We also analysed a subgroup of sibpairs with age at diagnosis younger than

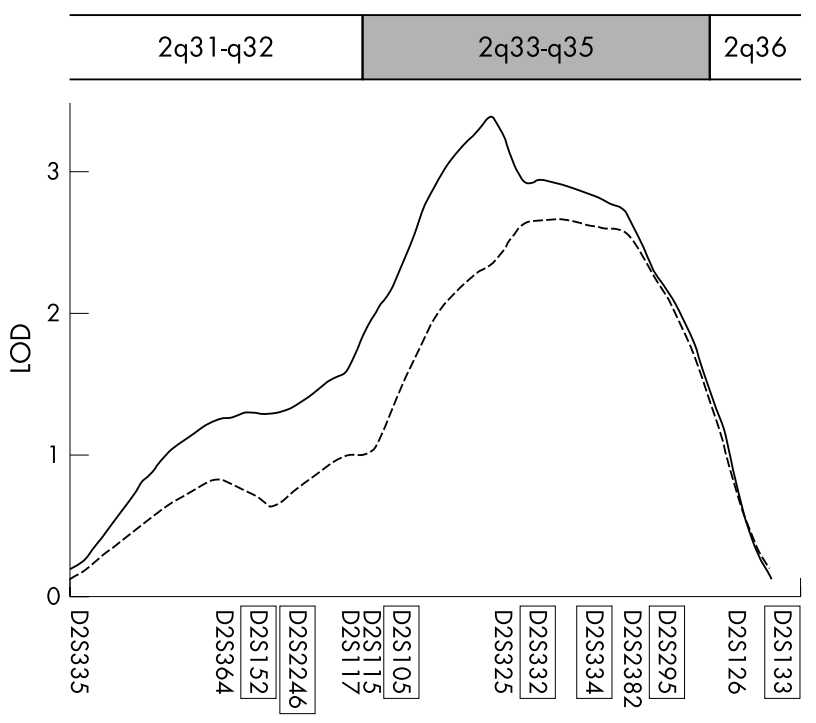

Figure 2 Multipoint linkage analysis using additional markers on chromosome 2q31-36 for the proximal gastric cancer subgroup using the MAPMAKER/SIBS (thick line) and MERLIN programs (dotted line). Reanalysis was carried out after genotyping seven additional markers (boxed).
50 years old. Even though the LOD scores were not high, two linkage signals were detected on chromosome 2q33-q35 and 21 q2 1 which also showed nominal evidence for linkage in an analysis of the entire data set (table 1).

Gastric cancer is a complex disease, and there are different etiologies, including environmental and genetic factors, for the different types. Previous studies indicate that gastric cardia cancer is less influenced by $H$. pylori infection, the main environmental risk factor, than non-cardia cancer. ${ }^{29-31}$ As the incidence of cardia cancer is reported to be stable, it may be that hereditary components have important roles in the tumourigenesis of this type of gastric cancer. Lagergren and co-workers reported that the risk of cardia cancer was moderately increased among persons with first degree relatives with gastric cancer in a nationwide case-control study in Sweden. ${ }^{32}$ This finding also supports a genetic link with cardia cancer. In this present study, we found that chromosome $2 \mathrm{q} 33-\mathrm{q} 35$ is a potential susceptibility locus for proximal gastric cancer. Data on the genome-wide scan presented here may contribute to a better understanding of genetic factors related to gastric cancer, particularly cardia cancer, although larger samples and additional ethnic populations will be needed.

\section{ACKNOWLEDGEMENTS}

We thank all patients and family members for participating in this study, T Tokuyasu, M Sonoda, K Fukuyama, M Obo, J Nakai, S Ohishi, N Tajiri, and T Akinaga, H Yamaguchi for technical services, and $\mathrm{M}$ Ohara for comments.

\section{ELECTRONIC-DATABASE INFORMATION}

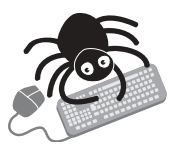

The URL for the National Center for Biotechnology Information is http://www.ncbi.nlm.nih.gov//http:// www.ncbi.nlm.nih.gov.

\section{Authors' affiliations}

M Aoki, K Sakai, K Yamamoto, Division of Molecular Population Genetics, Department of Molecular Genetics, Medical Institute of Bioregulation and COE Program on Lifestyle-Related Diseases, Kyushu University, Fukuoka, Japan

Y Yamamura, Department of Gastroenterological Surgery, Aichi Cancer Center Hospital, Nagoya, Japan

H Noshiro, Department of Surgery and Oncology, Graduate School of Medical Sciences, Kyushu University, Fukuoka, Japan

J Yokota, T Kohno, Biology Division, National Cancer Center Research Institute, Tokyo, Japan

T Tokino, S Ishida, Department of Molecular Biology, Cancer Research Institute, School of Medicine, Sapporo Medical University, Sapporo, Japan

S Ohyama, Department of GI Surgery, Cancer Institute Hospital, Tokyo, Japan

I Ninomiya, Gastroenterologic Surgery, Department of Oncology, Division of Cancer Medicine, Graduate School of Medical Science, Kanazawa University, Kanazawa, Japan

K Uesaka, Surgical Oncology, Nagoya University Graduate School of Medicine, Nagoya, Japan

M Kitajima, Department of Surgery, School of Medicine, Keio University, Tokyo, Japan

S Shimada, Second Department of Surgery, Kumamoto University School of Medicine, Kumamoto, Japan

S Matsuno, First Department of Surgery, Tohoku University School of Medicine, Sendai, Japan

M Yano, Department of Surgery and Clinical Oncology, Graduate School of Medicine, Osaka University, Osaka, Japan

M Hiratsuka, Department of Surgery, Osaka Medical Center for Cancer and Cardiovascular Diseases, Osaka, Japan

H Sugimura, Department of Pathology, Hamamatsu University School of Medicine, Hamamatsu, Japan

F Itoh, Department of Internal Medicine, St. Marianna University School of Medicine, Kawasaki, Japan 
T Minamoto, Division of Diagnostic Molecular Oncology and Surgical Oncology, Cancer Research Institute, Kanazawa University, Kanazawa, Japan

Y Maehara, Department of Surgery and Science, Graduate School of Medical Sciences, Kyushu University, Fukuoka, Japan

S Takenoshita, Second Department of Surgery, Fukushima Medical University, Fukushima, Japan

T Aikou, First Department of Surgery, Kagoshima University School of Medicine, Kagoshima, Japan

H Katai, National Cancer Center Hospital, Tokyo, Japan

K Yoshimura, Cancer Information and Epidemiology Division, National Cancer Center Research Institute, Tokyo, Japan

T Takahashi, Tokyo Metropolitan Komagome Hospital, Tokyo, Japan

K Akagi, Saitama Cancer Center Research Institute, Saitama, Japan

M Sairenii, Department of Gastrointestinal Surgery, Kanagawa Cancer Center, Yokohama, Japan

T Sasazuki, International Medical Center of Japan, Tokyo, Japan

This work was supported by a Grant-in-Aid for Scientific Research on Priority Areas 'Cancer', and a Grant from the 21 st COE Program from the Ministry of Education, Culture, Sports, Science and Technology, Japan.

Competing interests: none declared

Collaborators, listed in alphabetical order, are as follows: Shuichi Hokita (Kagoshima University), Masami Ikeda (Toho University), Kohzoh Imai (Sapporo Medical University), Osamu Ishikawa (Osaka Medical Center for Cancer and Cardiovascular Diseases), Hiroshi Kobayashi (Seirei Hamamatsu Hospital), Yasuhiro Kodera (Aichi Cancer Center Hospital), Tetsuro Kubota (Keio University), Masayoshi Mai (Kanazawa University), Mami Mihara (National Cancer Center), Koichi Miwa (Kanazawa University), Yohei Miyagi (Kanagawa Cancer Center Research Institute), Isao Miyashiro (Osaka Medical Center for Cancer and Cardiovascular Diseases), Morito Monden (Osaka University), Toshifusa Nakajima (Cancer Institute Hospital), Yuzo Nakaya (Seirei Hamamatsu Hospital), Noriko Noda (Nagoya University), Tadashi Nomizu (Hoshi General Hospital), Michio Ogawa (Kumamoto University), Yasushi Sasaki (Sapporo Medical University), Kenichi Shiiba (Tohoku University), Masao Tanaka (Kyushu University), and Akikuni Yagita (Kinki University).

Correspondence to: Takehiko Sasazuki, International Medical Center of Japan, 1-21-1 Toyama, Shinjuku-ku, Tokyo 162-8655, Japan; sasazuki@nciryo.hosp.go.jp

Revised version received 1 June 2004

Accepted for publication 2 June 2004

\section{REFERENCES}

1 Kobayashi M, Tsubono, Y, Sasazuki S, Sasaki S, Tsugane S. Vegetables, fruit and risk of gastric cancer in Japan: a 10-year follow-up of the JPHC Study Cohort I. Int J Cancer 2002;102:39-44.

2 Ekstrom AM, Serafini M, Nyren O, Hansson LE, Ye W, Wolk A. Dietary antioxidant intake and the risk of cardia cancer and noncardia cancer of the intestinal and diffuse types: a population-based case-control study in Sweden. Int J Cancer 2000;87: 133-40.

3 Sasazuki S, Sasaki S, Tsugane S. Japan Public Health Center Study Group. Cigarette smoking, alcohol consumption and subsequent gastric cancer risk by subsite and histologic type. Int J Cancer 2002;101:560-6.

4 Ekstrom AM, Hansson LE, Signorello LB, Lindgren A, Bergstrom R, Nyren O. Decreasing incidence of both major histologic subtypes of gastric adenocarcinoma - population-based study in Sweden. Br J Cancer 2000;83:391-6

5 Wu AH, Crabtree JE, Bernstein L, Hawtin P, Cockburn M, Tseng CC, Forman D. Role of Helicobacter pylori CagA+ strains and risk of adenocarcinoma of the stomach and esophagus. Int J Cancer 2003;103:815-21.

6 Chan AO, Lam SK, Wong BC, Wong WM, Yuen MF, Yeung YH, Hui WM, Rashid A, Kwong YL. Promoter methylation of E-cadherin gene in gastric mucosa associated with Helicobacter pylori infection and in gastric cancer. Gut 2003;52:502-6.
7 El-Omar EM, Rabkin CS, Gammon MD, Vaughan TL, Risch HA, Schoenberg JB, Stanford JL, Mayne ST, Goedert J, Blot WJ, Fraumeni JF Jr, Chow WH. Increased risk of noncardia gastric cancer associated with proinflammatory cytokine gene polymorphisms. Gastroenterology 2003;124: 1193-201.

8 Dhillon PK, Farrow DC, Vaughan TL, Chow WH, Risch HA, Gammon MD, Mayne ST, Stanford JL, Schoenberg JB, Ahsan H, Dubrow R, West AB, Rotterdam H, Blot WJ, Fraumeni JF Jr. Family history of cancer and risk of esophageal and gastric cancers in the United States. Int $J$ Cancer 2001;93:148-52

9 Dong C, Hemminki K. Modification of cancer risks in offspring by sibling and parental cancers from 2,112,616 nuclear families. Int J Cancer 2001;92:144-50.

10 Lichtenstein P, Holm NV, Verkasalo PK, Iliadou A, Kaprio J, Koskenvuo M, Pukkala E, Skythe A, Hemminki K. Environmental and heritable factors in the causation of cancer - analyses of cohorts of twins from Sweden, Denmark, and Finland. N Engl J Med 2000;343:78-85.

11 Gonzalez CA, Sala N, Capella G. Genetic susceptibility and gastric cancer risk. Int J Cancer 2002;100:249-60.

12 Guilford P, Hopkins J, Harraway J, McLeod M, McLeod N, Harawira P, Taite H, Scoular R, Miller A, Reeve AE. E-cadherin germline mutations in familial gastric cancer. Nature 1998;392:402-5.

13 Massad M, Uthman S, Obeid S, Majiar F. Ataxia-telangiectasia and stomach cancer. Am J Gastroenterol 1990:85:630-1.

14 Lee JH, Han SU, Cho H, Jennings B, Gerrard B, Dean M, Schmidt L, Zbar B, Vande Woude GF. A novel germ line juxtamembrane Met mutation in human gastric cancer. Oncogene 2000;19:4947-53.

15 Mecklin JP, Jarvinen HJ. Tumor spectrum in cancer family syndrome (hereditary nonpolyposis colorectal cancer). Cancer 1991;68:1109-12.

16 Li FP, Fraumeni JF Jr. Prospective study of a family cancer syndrome. JAMA 1982;247:2692-4.

17 lida M, Yao T, Itoh H, Watanabe H, Matsui T, Iwashita A, Fujishima M. Natural history of gastric adenomas in patients with familial adenomatosis coli/Gardner's syndrome. Cancer 1988;61:605-11.

18 Dodds WJ, Schulte WJ, Hensley GT, Hogan WJ. Peutz-Jeghers syndrome and gastrointestinal malignancy. Am J Roentgenol 1972;115:374-7.

19 Sakai K, Shirasawa S, Ishikawa N, Ito K, Tamai H, Kuma K, Akamizu T, Tanimura M, Furugaki K, Yamamoto K, Sasazuki T. Identification of susceptibility loci for autoimmune thyroid disease to $5 \mathrm{q} 31-\mathrm{q} 33$ and Hashimoto's thyroiditis to 8q23-q24 by multipoint affected sib-pair linkage analysis in Japanese. Hum Mol Genet 2001;10:1379-86.

20 Lander E, Kruglyak L. Genetic dissection of complex traits: guidelines for interpreting and reporting linkage results. Nat Genet 1995;1 1:241-7.

21 Abecasis GR, Cherny SS, Cookson WO, Cardon LR. Merlin-rapid analysis of dense genetic maps using sparse gene flow trees. Nat Genet 2002;30:97-101

22 Newnham A, Quinn MJ, Babb P, Kang JY, Majeed A. Trends in the subsite and morphology of oesophageal and gastric cancer in England and Wales 1971-1998. Aliment Pharmacol Ther 2003;17:665-76.

23 Terry MB, Gaudet MM, Gammon MD. The epidemiology of gastric cancer. Semin Radiat Oncol 2002;12:111-27.

24 Japanese Gastric Cancer Association. Japanese Classification of Gastric Carcinoma - 2nd English Edition. Gastric Cancer 1998;1:10-24.

25 Kelley JR, Duggan JM. Gastric cancer epidemiology and risk factors. J Clin Epidemiol 2003;56:1-9.

26 Ekstrom AM, Signorello LB, Hansson LE, Bergstrom R, Lindgren A, Nyren O. Evaluating gastric cancer misclassification: a potential explanation for the rise in cardia cancer incidence. J Natl Cancer Inst 1999;91:786-90.

27 Lauren PA, Nevalainen TJ. Epidemiology of intestinal and diffuse types of gastric cancer. A time-trend study in Finland with comparison between studies from high- and low-risk areas. Cancer 1993;71:2926-33.

28 Roder DM. The epidemiology of gastric cancer. Gastric Cancer 2002;5(suppl 1):5-11.

29 Parsonnet J, Friedman GD, Vandersteen DP, Chang Y, Vogelman JH, Orentreich N, Sibley RK. Helicobacter pylori infection and the risk of gastric carcinoma. N Engl J Med 1991;325:1127-31

30 Helicobacter and Cancer Collaborative Group. Gastric cancer and Helicobacter pylori: a combined analysis of 12 case control studies nested within prospective cohorts. Gut 2001;49:347-53.

31 Driessen A, Van Raemdonck D, De Leyn P, Filez L, Peeters M, Winnepenninckx V, Penninckx F, Lerut T, Ectors N. H.P. Belgian Contact Group. Are carcinomas of the cardia oesophageal or gastric adenocarcinomas? Eur J Cancer 2003;39:2487-94.

32 Lagergren J, Ye W, Lindgren A, Nyren O. Heredity and risk of cancer of the esophagus and gastric cardia. Cancer Epidemiol Biomarkers Prev 2000;9:757-60. 